\title{
BMJ Open Frequency of TV viewing and prevalence of overweight and obesity among adult women in Bangladesh: a cross-sectional study
}

\author{
Bishwajit Ghose
}

To cite: Ghose B. Frequency of TV viewing and prevalence of overweight and obesity among adult women in Bangladesh: a cross-sectional study. BMJ Open 2017;7: e014399. doi:10.1136/ bmjopen-2016-014399

- Prepublication history for this paper is available online. To view these files please visit the journal online (http://dx.doi.org/10.1136/ bmjopen-2016-014399).

Received 21 September 2016 Revised 11 January 2017 Accepted 12 January 2017

CrossMark

Institute of Nutrition and Food Science, University of Dhaka, Dhaka, Bangladesh brammaputram@gmail.com

Correspondence to Dr Bishwajit Ghose; brammaputram@gmail.com

\section{ABSTRACT}

Background: Research in developed countries has demonstrated an association of varying degrees between watching TV and the risk of being overweight and obese. However, there is no evidence of such an association in the context of the South Asian population. Objective: To investigate whether watching TV increases the risk of being overweight and obese among women in Bangladesh.

Setting: Rural and urban areas in Bangladesh. Participants: Participants were 16624 non-pregnant women aged between 15 and 49 years.

Methods: The study was based on cross-sectional data from the Bangladesh Demographic and Health Survey (BDHS) conducted in 2014. The main outcome variables were overweight and obesity measured by body mass index. Data were analysed by using descriptive statistics, cross-tabulation and multivariable logistic regression models.

Results: The prevalence of overweight and obesity in the sample population were, respectively, $4.5 \%(4.18 \%$ to $4.82 \%$ ) and $20 \%(95 \% \mathrm{Cl} 19.39 \%$ to $20.61 \%)$. In the multivariable analysis, no statistically significant association was found between watching TV and being overweight. However, the odds of being obese among rural women were 63\% higher (adjusted OR (AOR) $1.625,95 \% \mathrm{Cl} 1.179$ to 2.241 ) among those who watched less than once a week, and 68\% (AOR 1.683, $95 \% \mathrm{Cl} 1.029$ to 2.751 ) higher among women who watched TV at least once a week compared to those who did not watch TV at all. Urban women who watched TV at least once a week were $67 \%$ more likely to be obese (AOR 1.665, 95\% Cl 1.079 to 2.568) compared to those who did not watch at all.

Conclusions: Prevalence of overweight and obesity has risen considerably among women aged between 15 and 49 years since the previous estimates based on BDHS data. Frequent TV watching was associated with a higher risk of being obese among adult women in rural areas.

\section{INTRODUCTION}

Overweight and obesity represent major risk factors for non-communicable chronic

\section{Strengths and limitations of this study}

This is the first study to investigate the association between TV viewing and overweight/obesity among adult women in a South Asian country.

- The sample size was large and representative of the general population.

- TV viewing frequency per week was used instead of duration per day which could have produced a more precise picture of the association.

- Data were cross-sectional, which precludes any causal inference.

diseases (NCDs), and are considered major public health hazards in low and middle income countries and in developed countries. $^{1} \quad 2$ In 2010, worldwide about 3.4 million deaths, $3.9 \%$ of years of life lost, and $3.8 \%$ of disability-adjusted life-years (DALYs) were attributable to overweight/obesity alone. ${ }^{3}$ In Bangladesh, where the epidemiological trend is usually characterised by high rates of infectious diseases ${ }^{4}$ along with childhood and adult undernutrition, overweight and obesity are fast becoming a significant public health concern. ${ }^{5}$ The prevalence of overweight and obesity increased about twofold during the period 2004-2011: overweight $7.5 \%$ in 2004 versus $13.5 \%$ in 2011, and obesity $1.4 \%$ in 2004 versus $2.9 \%$ in 2011. ${ }^{6}$ This rising prevalence is usually attributed to the recent economic progress which has been accompanied by certain demographic and nutritional transitions, urbanisation, and dietary and lifestyle changes. $^{5} 7$ Review of the epidemiological studies surrounding the determinants of overweight/obesity suggests attention is growing in regard to the impact of lifestyle related obesogenic behaviours. ${ }^{8-10}$ Factors that appear most commonly include changing dietary choices, sedentary behaviour, watching TV, playing computer games, and level of physical activity (PA). ${ }^{5-10}$ 
A growing consensus suggests a strong correlation between sedentary lifestyle and inadequate PA and the risk of developing NCDs. ${ }^{7}{ }^{9-11}$ Studies from low and middle income countries have shown that a large proportion of children and adolescents do not meet recommended levels of PA, as lifestyles involving higher PA have been displaced by more sedentary alternatives (satellite TV, computer games, telecommunication technology), thus contributing to reduced PA and energy expenditure. ${ }^{12}$ It has been claimed that watching TV not only leads to reduced levels of PA, but involves a set of behaviours whereby sitting/lying is the dominant mode of posture with low energy expenditure, and that getting used to such postural behaviour can be replicated at school and in the workplace. ${ }^{13}$ Higher sitting time has been shown to be associated with increased risk of developing overweight and obesity, cancer, and diabetes ${ }^{14} 15$ and has been identified as a global public health issue. ${ }^{16}$ In addition to reduced levels of PA and low energy expenditure, TV watching also increases the consumption of obesogenic foods. ${ }^{17}$ Cross-sectional studies on American and Latino children reported that watching TV during family meals is associated with reduced consumption of fruit and vegetables and higher consumption of soda, chips and sausages. ${ }^{17}{ }^{18}$ However, the levels and type of food intake can depend on the genre of programme being watched and the level of engagement. ${ }^{19}$

Arguably, the frequency and duration of TV watching can vary substantially from person to person, depending on the availability of alternative sources of recreation, availability of resources of PA, and social factors that can impact the freedom of movement (eg, age, gender, dietary habit, sociocultural factors, neighbourhood safety, level of socialisation). Therefore, the association between TV viewing and being overweight/obese is not generalisable and needs to be studied and interpreted by taking the local context into consideration. Current evidence on this topic is mostly derived from low and middle income countries with very limited research in South Asian countries. Major barriers to conducting studies in this area are lack of recognition of the problem and want of country-wide data. The present study aims to address the research gap by utilising data from the Bangladesh Demographic and Health Survey (BDHS) 2014 survey which provides quality data on various health indicators for women and children in the country. BDHS does not include any separate section on hours of TV watching, hence the number of days/week, instead of hours and minutes, was used as a proxy measure of duration of TV watching.

\section{METHODS}

\section{Study setting}

Bangladesh is the third largest country in the South Asian region and also has the third largest economy in terms of gross domestic product (GDP). It is the most densely populated country in the world with a population density of 1070 persons $/ \mathrm{km}^{2}$ (2014 estimate). The life expectancy at birth among women is 72 years versus 69 years among men. Though the economy has been experiencing unprecedented progress in the last few decades, the country's performance is still very low in terms of the Human Development Index (HDI value for 2014 is 0.570 ), ranking 142nd out of 188 countries (fifth in South Asia). The World Bank classifies Bangladesh as a lower middle income country with a gross national income (GNI) per capita of US $\$ 1314$ in the fiscal year 2014-2015. ${ }^{20}$

\section{Survey and data collection}

The 2014 BDHS was the sixth survey of its kind to take place in the country. The main objectives of the survey were to provide quality data on a range of health, demographic, and socioeconomic indicators and assist in evidence-based policymaking. The survey was conducted under the authority of the National Institute of Population Research and Training (NIPORT) of the Ministry of Health and Family Welfare and was implemented by Mitra and Associates with technical assistance from ICF International of Rockville, Maryland, USA, and financial support from the US Agency for International Development (USAID). Data collection lasted from 28 June to 9 November 2014.

Bangladesh has seven administrative regions which are divided into 64 districts. The sample population covered the residents in non-institutional dwellings in both urban and rural areas from all 64 districts. The primary sampling units (PSU) for the survey were enumeration areas (EAs) used in the Population and Housing Census in the country in 2011 that was provided by the Bangladesh Bureau of Statistics (BBS). Each EA is a collection of an average of about 120 households. At first, 600 EAs were selected for the survey with 207 EAs in urban areas and 393 in rural areas. In the second stage, on average 30 households were selected from each EA, which summed to about 18000 households. The 2014 BDHS used three types of questionnaires: Household, Woman's Questionnaire, and Community Questionnaire. The main purpose of the Household Questionnaire was to identify women eligible for the individual interview. A total of 18245 ever-married women aged between 15 and 49 years were identified in these households from which 17863 were finally interviewed, producing a response rate of $98 \%$. Data for the present study were extracted from the Woman's Questionnaire which included themes such as basic sociodemographic, anthropometric, reproductive, fertility, immunisation, and HIV knowledge. ${ }^{41}$ Details of the survey are available in the final report published by NIPORT. ${ }^{21}$

\section{Study variables}

The outcome variables for this study were overweight and obesity measured by body mass index (BMI), which was defined as weight in $\mathrm{kg}$ divided by height in $\mathrm{m}^{2}$. BDHS carries out anthropometric measurements such 
as height and weight for ever-married women aged 1549 years as an indicator of women's nutritional status. As per WHO recommendations, women were categorised as neither overweight nor obese when BMI was $<25 \mathrm{~kg}$ / $\mathrm{m}^{2}$, overweight if BMI was $25-29.9 \mathrm{~kg} / \mathrm{m}^{2}$ and obese if BMI was $>30 \mathrm{~kg} / \mathrm{m}^{2}$. Exclusion criteria were being currently pregnant and non-availability of information on height and/or weight.

The explanatory variable of main interest was 'frequency of TV watching'. As the exact durations (hours or minutes/day) were not available, the frequencies per week were used as a proxy measure which included: (1) not watching TV at all, (2) watching less than once a week, and (3) watching at least once a week.

Based on insights from reviewing the literature, the following covariates were deemed relevant to the topic and for inclusion in the study-age: 15-24/25-34/ >35 years; division: Barisal/Chittagong/Dhaka/Khulna/ Rajshahi/Rangpur/Sylhet; educational attainment*: nil/ primary/secondary/higher; husband's educational attainment: nil/primary/secondary/higher; currently employed: yes/no; wealth index**: poorest/poorer/ middle/richer/richest; parity: 1/2/3/3+.

*Educational attainment was categorised as per the highest level/class attended, regardless of the completion status of that level/class. Nil refers to no experience of formal education, primary as completing grade 5, secondary as completing grade 10, and higher as those who had pre-university/university level education.

**BDHS surveys provided information on wealth status instead of any direct information on income. Household Wealth Index is a used as a proxy measure for household living status which takes into consideration household possessions (eg, TV, radio, bicycle) and housing quality (eg, type of floor, wall, and roof). Calculation of the wealth index consists of assigning a factor score for a set of possessions which is generated through principal component analysis (PCA). The scores are then summed and standardised for each household which places them in a continuous scale based on relative wealth scores. Finally, the scores are categorised into quintiles where each household fall into a category, with the lowest scores representing the poorest and the highest scores representing the richest households. ${ }^{17}$

\section{Data analysis}

Data were analysed using STATA V.12 and SPSS V.20. Datasets were checked for missing values and outliers. Weighted baseline sociodemographic information was presented by descriptive statistics. $\chi^{2}$ tests were performed to examine the group differences (between overweight and obesity) for all the explanatory variables. The variables that showed significance at $p \leq 0.25$ were selected for final regression analysis. All variables were checked for multicollinearity and no significant multicollinearity was observed between any variables. The association between BMI and frequency of TV watching was measured by means of multinomial logistic regression. Results of the regression analysis were presented as crude and adjusted ORs with corresponding 95\% CIs. All tests were two-tailed and were considered significant at the level of $5 \%$.

\section{Ethics statement}

All participants gave informed consent before taking part in the voluntary interview. The survey was approved by the ICF International Institutional Review Board which is responsible for reviewing the procedures and questionnaires for standard BDHS surveys.

\section{RESULTS}

Basic characteristics of the sample population are presented in table 1 . The table shows that the majority of the women were of rural origin with the highest participation from the Dhaka division (17.4\%) and the lowest from Sylhet $(11.3 \%)$. More than a quarter of the women were in the 15-24 years age group and more than one-third were above 34 years of age, and about two-thirds $(65.3 \%)$ were of rural origin. The rate of having no formal education was higher among women compared to their husbands $(75.7 \%$ vs $71.3 \%)$. The majority of the women $(37 \%)$ and their husbands $(29.4 \%)$ had secondary school level qualification. However, the rate of completion of higher education was lower among women $(9.4 \%)$ compared to their husbands $(14.9 \%)$. Less than one-third of the women reported being in employment at the time of interview, and the rate of unemployment was slightly higher among urban women compared to rural women $(68.8 \%$ vs $66.8 \%$ ). Regarding household wealth status, the majority of the women belonged to the wealthiest group $(21.7 \%)$. However, the rate of being in the wealthiest group was noticeably higher among urban women compared to their rural counterparts $(44.4 \%$ vs $9.6 \%)$. More than one-fifth of the women were primiparous and a little less than one-third of the women had experienced more than three childbirths. About two-fifths of the women reported not watching TV at all $(39.4 \%)$ and more than half reported watching at least once a week. The rate of watching TV at least once a week was almost twice as high among urban women compared to rural women $(75.1 \%$ vs $39.6 \%)$. The prevalence of overweight and obesity in the sample population were, respectively, $4.5 \%$ and $20 \%$. Urban women had a higher prevalence of both overweight $(27.7 \%$ vs $15.9 \%)$ and obesity $(8.1 \%$ vs $2.6 \%$ ) compared to rural women.

\section{Cross-tabulation}

Table 2 shows the results of $\chi^{2}$ tests of association among the three groups according to their BMI status in relation to the explanatory variables. The results show that the prevalence of both overweight and obesity increased with higher age and was most common in Dhaka division. Women who had secondary level education, were currently unemployed, belonged to the wealthier 
Table 1 Baseline characteristics of the study population, BDHS 2014

\begin{tabular}{|c|c|}
\hline Variables & Frequency (\%) \\
\hline \multicolumn{2}{|l|}{ Age (years) } \\
\hline $15-24$ & $4433(26.7)$ \\
\hline $25-34$ & 5969 (35.9) \\
\hline $35 / 35+$ & $6222(37.4)$ \\
\hline \multicolumn{2}{|l|}{ Division } \\
\hline Barisal & $1982(11.9)$ \\
\hline Chittagong & 2639 (15.9) \\
\hline Dhaka & $2893(17.4)$ \\
\hline Khulna & $2460(14.8)$ \\
\hline Rajshahi & 2380 (14.3) \\
\hline Rangpur & $2389(14.4)$ \\
\hline Sylhet & $1881(11.3)$ \\
\hline \multicolumn{2}{|l|}{ Residency } \\
\hline Urban & $5764(34.7)$ \\
\hline Rural & $10860(65.3)$ \\
\hline \multicolumn{2}{|l|}{ Educational attainment } \\
\hline Nil & 4039 (24.3) \\
\hline Primary & 4875 (29.3) \\
\hline Secondary & $6153(37.0)$ \\
\hline Higher & $1557(9.4)$ \\
\hline \multicolumn{2}{|c|}{ Husbands' educational attainment } \\
\hline Nil & $4764(28.7)$ \\
\hline Primary & $4503(27.1)$ \\
\hline Secondary & $4884(29.4)$ \\
\hline Higher & 2473 (14.9) \\
\hline \multicolumn{2}{|l|}{ Currently employment } \\
\hline No & $11221(67.5)$ \\
\hline Yes & $5403(32.5)$ \\
\hline \multicolumn{2}{|l|}{ Wealth index } \\
\hline Poorest & 2999 (18.0) \\
\hline Poorer & 3102 (18.7) \\
\hline Middle & 3382 (20.3) \\
\hline Richer & 3534 (21.3) \\
\hline Richest & 3607 (21.7) \\
\hline \multicolumn{2}{|l|}{ Parity } \\
\hline 1 & 3625 (21.8) \\
\hline 2 & $4495(27.0)$ \\
\hline 3 & 3238 (19.5) \\
\hline $3+$ & 5266 (31.7) \\
\hline \multicolumn{2}{|l|}{ Frequency of watching TV } \\
\hline Not at all & $6544(39.4)$ \\
\hline Less than once a week & $1453(8.7)$ \\
\hline At least once a week & 8627 (51.9) \\
\hline \multicolumn{2}{|l|}{ BMI } \\
\hline $\mathrm{BMI} \geq 30$ & $748(4.2)$ \\
\hline $25 \geq \mathrm{BMI}<30$ & 3325 (20.0) \\
\hline $\mathrm{BMI}<25$ & $12551(75.8)$ \\
\hline
\end{tabular}

households, and had two children were more likely to be overweight and obese. Participants who reported watching TV at least once a week were also more likely to be overweight and obese compared to those who did not watch at all or watched less than once a week.

The association between frequency of TV watching and BMI status among the sample population was analysed by means of multivariable logistic regression, with normal weight considered as the reference group. The crude and adjusted odds of being overweight and obese are shown in tables 3 and 4, respectively. Compared with women who did not watch TV at all, those who watched at least once a week were $84 \%$ (adjusted OR (AOR) $1.840,95 \%$ CI 1.215 to 2.788 ) and $58 \%$ (AOR $1.578,95 \%$ CI 1.189 to 2.094 ) more likely to be overweight in urban and rural areas, respectively. Urban women who watched TV less than once and at least once per week were 2.1 (AOR 2.075, 95\% CI 1.341 to 3.211 ) ) and 4.7 (AOR $4.705,95 \%$ CI 3.184 to 6.954 ) times more likely to be obese compared to those who did not watch TV at all. The corresponding figures for rural women were, respectively, 2.64 (AOR 2.643, 95\% CI 1.639 to 4.264 ) and 3.6 (AOR 3.611, 95\% CI 2.761 to 4.722).

In the adjusted model, however, no statistically significant association was found between TV viewing and being overweight. Urban women who watched TV at least once a week were $67 \%$ more likely to be obese (AOR $1.665,95 \%$ CI 1.079 to 2.568 ) compared to those who did not watch at all. In the rural areas, women who watched TV less than once and at least once per week had, respectively, 63\% (AOR 1.625, 95\% CI 1.179 to 2.241 ) and $68 \%$ (AOR 1.683, 95\% CI 1.029 to 2.751) higher odds of being obese compared to those who did not watch TV at all.

Model goodness-of-fit: Several goodness-of-fit statistics are used to check for internal validity of regression models. However, for this study McFadden $\mathrm{R}^{2}$ value was used as it is one of the most commonly reported. The McFadden $\mathrm{R}^{2}$ was 0.197 in the adjusted model, indicating a satisfactory model fitness.

\section{DISCUSSION}

\section{Main findings}

Based on nationally representative cross-sectional data, this study attempted to show the current prevalence of overweight and obesity among non-pregnant adult women in Bangladesh, and the association between frequency of TV viewing and being overweight and obese. Our findings indicate a net increase in the prevalence of overweight and obesity among women aged between 15 and 49 years. In the 2004 BDHS, which was the first to include anthropometric measurements for adult women, the prevalence of women with $\mathrm{BMI} \geq 25.0$ was $8.9 \% \quad(7.5 \%$ overweight and $1.4 \%$ obese $)$, which increased to $16.4 \%$ ( $13.5 \%$ overweight and $2.9 \%$ obese) in 2011 and $24 \%$ ( $19.4 \%$ overweight and $4.4 \%$ obese) in 2014. As seen in the previous surveys, urban women had a notably higher prevalence of both overweight $(27.7 \%$ vs $15.9 \%)$ and obesity $(8.1 \%$ vs $2.6 \%)$ compared to their rural counterparts.

As expected, the frequency of TV watching was also higher among women in urban areas than in rural areas. This is understandable as urban residents enjoy a 
Table 2 Prevalence of overweight and obesity in the sample population across the explanatory variables, BDHS 2014

\begin{tabular}{|c|c|c|c|c|c|}
\hline \multirow[b]{2}{*}{ Variables } & \multicolumn{3}{|c|}{ BMI status (\%) } & \multirow[b]{2}{*}{$\chi^{2}$} & \multirow[b]{2}{*}{ p Value } \\
\hline & $\mathrm{BMI} \geq \mathbf{3 0}$ & $25 \geq \mathrm{BMI}<30$ & BMI $<25$ & & \\
\hline Age (years) & & & & 428.111 & $<0.0001$ \\
\hline $15-24$ & 10.6 & 15.5 & 30.6 & & \\
\hline $25-34$ & 37.2 & 41.2 & 34.4 & & \\
\hline $35 / 35+$ & 52.3 & 43.3 & 35.0 & & \\
\hline Division & & & & 176.299 & $<0.0001$ \\
\hline Barisal & 8.7 & 10.5 & 12.5 & & \\
\hline Chittagong & 18.7 & 18.2 & 15.1 & & \\
\hline Dhaka & 20.1 & 19.8 & 16.6 & & \\
\hline Khulna & 18.4 & 17.4 & 13.9 & & \\
\hline Rajshahi & 15.5 & 14.7 & 14.2 & & \\
\hline Rangpur & 10.2 & 11.3 & 15.4 & & \\
\hline Sylhet & 8.4 & 8.0 & 12.4 & & \\
\hline \multicolumn{6}{|l|}{ Residency } \\
\hline Urban & 62.3 & 48.1 & 29.5 & 664562 & $<0.0001$ \\
\hline Rural & 37.7 & 51.9 & 70.5 & & \\
\hline Educational attainment & & & & 434.825 & 0.001 \\
\hline $\mathrm{Nil}$ & 14.2 & 17.1 & 26.8 & & \\
\hline Primary & 23.9 & 25.4 & 30.7 & & \\
\hline Secondary & 44.9 & 42.2 & 35.2 & & \\
\hline Higher & 17.0 & 15.2 & 7.4 & & \\
\hline Husbands' educational attainment & & & & 758.122 & $<0.0001$ \\
\hline Nil & 14.8 & 18.6 & 32.1 & & \\
\hline Primary & 20.1 & 22.7 & 28.7 & & \\
\hline Secondary & 34.8 & 33.8 & 27.9 & & \\
\hline Higher & 30.3 & 24.8 & 11.3 & & \\
\hline Currently employment & & & & 53.861 & $<0.0001$ \\
\hline No & 77.8 & 69.9 & 66.2 & & \\
\hline Yes & 22.2 & 30.1 & 33.8 & & \\
\hline Wealth index & & & & 36.790 & 0.013 \\
\hline Poorest & 3.3 & 7.5 & 21.7 & & \\
\hline Poorer & 4.8 & 11.1 & 21.5 & & \\
\hline Middle & 12.0 & 17.4 & 21.6 & & \\
\hline Richer & 23.7 & 24.7 & 20.2 & & \\
\hline Richest & 56.1 & 39.2 & 15.0 & & \\
\hline Parity & & & & 154.802 & 0.004 \\
\hline 1 & 18.7 & 19.3 & 22.7 & & \\
\hline 2 & 31.8 & 33.1 & 25.1 & & \\
\hline 3 & 25.1 & 20.9 & 18.8 & & \\
\hline $3+$ & 24.3 & 26.7 & 33.4 & & \\
\hline Frequency of watching TV & & & & 18.898 & 0.001 \\
\hline Not at all & 14.2 & 23.9 & 45.0 & & \\
\hline Less than once a week & 5.6 & 7.6 & 9.2 & & \\
\hline At least once a week & 80.2 & 68.5 & 45.8 & & \\
\hline
\end{tabular}

BDHS, Bangladesh Demographic and Health Survey; BMI, body mass index.

Table 3 Association (crude) between frequency of watching TV and overweight and obesity among Bangladeshi women, BDHS 2014

\begin{tabular}{|c|c|c|c|c|}
\hline \multirow{2}{*}{$\begin{array}{l}\text { Frequency of } \\
\text { watching TV }\end{array}$} & \multicolumn{2}{|c|}{ Overweight (COR, 95\% Cl) } & \multicolumn{2}{|l|}{ Obesity (COR, 95\% Cl) } \\
\hline & Urban & Rural & Urban & Rural \\
\hline Not at all & 1 & 1 & 1 & 1 \\
\hline Less than once a week & $1.412(0.887$ to 2.248$)$ & 1.542 (0.933 to 2.549$)$ & $2.075(1.341$ to 3.211$)$ & 2.643 (1.639 to 4.264$)$ \\
\hline At least once a week & 1.840 (1.215 to 2.788$)$ & 1.578 (1.189 to 2.094$)$ & 4.705 (3.184 to 6.954$)$ & 3.611 (2.761 to 4.722$)$ \\
\hline
\end{tabular}


Table 4 Association (adjusted) between frequency of watching TV and overweight and obesity among Bangladeshi women, BDHS 2014

\begin{tabular}{|c|c|c|c|c|}
\hline \multirow{2}{*}{$\begin{array}{l}\text { Frequency of } \\
\text { watching TV }\end{array}$} & \multicolumn{2}{|c|}{ Overweight (AOR, 95\% Cl) } & \multicolumn{2}{|l|}{ Obesity (AOR, 95\% Cl) } \\
\hline & Urban & Rural & Urban & Rural \\
\hline Not at all & 1 & 1 & 1 & 1 \\
\hline Less than once a week & $1.173(0.728$ to 1.891$)$ & 1.258 (0.899 to 1.761$)$ & $1.210(0.763$ to 1.919$)$ & 1.625 (1.179 to 2.241$)$ \\
\hline At least once a week & $1.261(0.801$ to 1.985$)$ & $1.352(0.810$ to 2.257$)$ & 1.665 (1.079 to 2.568$)$ & $1.683(1.029$ to 2.751$)$ \\
\hline
\end{tabular}

higher coverage of electric grids and access to more diverse TV channels. Another possible reason can be the higher rate of employment among rural women which may allow them less time for recreation. TV watching was significantly associated with obesity among rural women. Women who reported watching TV less than once a week had higher odds of being obese compared to those who did not watch TV at all. Those who watched at least once a week had the highest likelihood of being overweight and obese. Regardless of the frequency of watching TV, urban women had higher odds of being obese than their rural counterparts. This might be due to the type of work they were engaged in and the types of food consumed. Types of employment in rural areas are supposed to be more labour consuming and involve greater movement due to less developed transportation and technological infrastructure. Moreover, the dietary environment in rural areas is also supposed to be less obesogenic than in urban areas due to the lower concentration of fast-food, restaurant and supermarket chains.

\section{Comparison with previous studies}

The prevalence of overweight and obesity is rising not only in Bangladesh but also in other South Asian countries, with varying trends across age, sex and region. In India, the percentage of overweight and obese women aged $15-49$ years rose from $11 \%$ in the National Family Health Survey (NFHS)-2 to $15 \%$ in NFHS-3, with the highest rates in Punjab (29.9\%) followed by Kerala $(28.1 \%)$ and Delhi $(26.4 \%){ }^{22}$ According to WHO estimates, the percentage of overweight and obesity among Pakistani women was, respectively, $25.5 \%$ and $3.6 \%$ with a higher prevalence of overweight and obesity among women than among men. ${ }^{23}$ For Nepal, the increase in the combined prevalence of overweight and obesity was about six times $(1.6 \%$ in 1996 vs $10.1 \%$ in 2006) between 1996 and 2006. ${ }^{24}$

Evidence regarding the association between TV viewing and overweight and obesity in South Asia is scarce; however, studies from other countries show that TV viewing is strongly associated with overweight and obesity among preschool children, adolescents and adults of both sexes, ${ }^{25-29}$ which is consistent with our findings in adult women in Bangladesh. Similar findings were observed in the USA, ${ }^{25}$ Japan $^{28}$ and Australia. ${ }^{29}$
Among Iranian adolescents, TV viewing was associated with increasing rates of overweight and obesity independent of PA and consumption of obesogenic foods. ${ }^{27}$ One review study proposed that TV viewing may act through mechanisms other than reducing the expenditure of energy and increasing the consumption of obesogenic foods, ${ }^{30}$ as the amount of obesogenic food consumption is not always related to the length of time the adolescents spent watching $\mathrm{TV}^{31}$

\section{RESEARCH IMPLICATIONS AND GENERAL DISCUSSION}

Recent research evidence suggests a rapid rise in the burden of overweight/obesity and associated NCDs, which is a growing concern for the underdeveloped healthcare system in Bangladesh. As the country is progressing in terms of socioeconomic development and improved living standards, more and more people are adopting modern technological conveniences and embracing a more western lifestyle. The literacy rate is still low and the general population is largely unaware of the consequences of unhealthy behaviour and lifestyle related risk factors of overweight/obesity and NCDs. Given the rising prevalence of overweight and obesity in the country, there is an urgent need for health policymakers to develop socio-culturally appropriate guidelines and create the opportunities for averting the onset of overweight/obesity among children, and implement interventions among those already overweight and obese. This is certainly a challenging task, the effective implementation of which is reliant on evidence from large scale population-based studies. Though the present study is very limited in its scope, it sets out the path for more in-depth studies to probe into the underlying determinants of inadequate PA and TV watching and the mechanisms through which they are contributing to the increasing prevalence of overweight/obesity among adult women in particular and the population in general.

\section{Strengths and limitations}

This study has several important strengths and limitations. To our knowledge, this is the first nationally representative study to investigate the frequency of TV viewing in relation to overweight/obesity among Bangladeshi women, so the findings are generalisable for adult 
women below the age of 50 years in Bangladesh. The findings are expected to serve as useful tools for developing proper intervention methods. However, as the survey collected data on outcome and explanatory variables at the same point in time, no causal inferences can be made. Secondly, TV viewing frequency per week was used instead of duration per day which could have produced more precise data on the exact number of hours of TV watching. More importantly, women reported the frequency themselves which may be subject to reporting bias and recall error. Future surveys are recommended to focus on the impact of the total number of hours instead of days and also include information on dietary and other behaviours associated with watching TV.

Acknowledgements The author would like extend sincere thanks to the BDHS for providing the data, and to the participants who agreed to take part in the survey.

Contributors BG was responsible for data collection, conceptualisation of the study, data analysis, and preparation of the manuscript.

Funding This research received no specific grant from any funding agency in the public, commercial or not-for-profit sectors.

Competing interests None declared.

Ethics approval Bangladesh Demographic and Health Survey.

Provenance and peer review Not commissioned; externally peer reviewed.

Data sharing statement Dataset used for this study was obtained from the BDHS website. The BDHS holds the sole authority to distribute the data through the public domain which is available at: http://dhsprogram.com/data/ available-datasets.cfm.

\section{Informed consent Obtained.}

Open Access This is an Open Access article distributed in accordance with the Creative Commons Attribution Non Commercial (CC BY-NC 4.0) license, which permits others to distribute, remix, adapt, build upon this work noncommercially, and license their derivative works on different terms, provided the original work is properly cited and the use is non-commercial. See: http:// creativecommons.org/licenses/by-nc/4.0/

\section{REFERENCES}

1. Nguyen DM, El-Serag HB. The epidemiology of obesity. Gastroenterol Clin North Am 2010;39:1-7.

2. Prentice AM. The emerging epidemic of obesity in developing countries. Int J Epidemiol 2006;35:93-9.

3. Ng M, Fleming T, Robinson M, et al. Global, regional, and national prevalence of overweight and obesity in children and adults during 1980-2013: a systematic analysis for the Global Burden of Disease Study 2013. Lancet 2014;384:766-81.

4. Yaya S, Bishwajit G, Danhoundo G, et al. Extent of knowledge about HIV and its determinants among men in Bangladesh. Front Public Health 2016;4:246.

5. Bishwajit G. Nutrition transition in South Asia: the emergence of non-communicable chronic diseases. Version 2. F1000Res 2015;4:8.

6. Kamal SSM, Che HH, Alam GM. Dual burden of underweight and overweight among women in Bangladesh: patterns, prevalence, and sociodemographic correlates. J Health Pop Nutr, 2015;33:92-105.

7. Dennison M, Sisson SB, Morris A. Obesogenic behaviours and depressive symptoms in children: a narrative literature review. Obes Rev 2016;17:735-57.
8. Sisson SB, Krampe M, Anundson $\mathrm{K}$, et al. Obesity prevention and obesogenic behavior interventions in child care: a systematic review. Prev Med 2016;87:57-69.

9. Sikorski C, Luppa M, Weyerer S, et al. Obesity and associated lifestyle in a large sample of multi-morbid German primary care attendees. PLoS One 2014;9:e102587.

10. Hills AP, Andersen LB, Byrne NM. Physical activity and obesity in children. Br J Sports Med 2011;45:866-70.

11. Poirier $P$, Després JP. Exercise in weight management of obesity. Cardiol Clin 2001;19:459-70.

12. Tang S, Bishwajit G, Ji L, et al. Improving the blood pressure control with the proactive attitude of hypertensive patients seeking follow-up services: evidence from China. Medicine (Baltimore) 2016;95:e3233.

13. Sedentary Behaviour and Obesity Expert Working Group. Sedentary behaviour and obesity: review of the current scientific evidence. London, UK: Department of Health, 2010.

14. Healy GN, Wijndaele K, Dunstan DW, et al. Objectively measured sedentary time, physical activity, and metabolic risk: the Australian Diabetes, Obesity and Lifestyle Study (AusDiab). Diabetes Care 2008;31:369-71.

15. Zhang $\mathrm{M}, \mathrm{Xie} \mathbf{X}$, Lee $\mathrm{AH}$, et al. Sedentary behaviours and epithelial ovarian cancer risk. Cancer Causes Control 2004;15:83-9.

16. Owen N, Healy GN, Matthews CE, et al. Too much sitting: the population health science of sedentary behavior. Exerc Sport Sci Rev 2010;38:105-13.

17. Robinson TN. Reducing children's television viewing to prevent obesity: a randomized controlled trial. JAMA 1999;282:1561-7.

18. Fitzpatrick E, Edmunds LS, Dennison BA. Positive effects of family dinner are undone by television viewing. J Am Diet Assoc 2007;107:666-71.

19. Chapman CD, Nilsson VC, Thune HÅ et al. Watching TV and food intake: the role of content. PLOS One 2014;9:e100602.

20. National Institute of Population Research and Training (NIPORT), Mitra and Associates, and ICF International. 2016. Bangladesh demographic and health survey 2014. Rockville, MA, USA: NIPORT, Mitra and Associates, and ICF International.

21. Yaya S, Bishwajit G, Danhoundo G, et al. Trends and determinants of HIV/AIDS knowledge among women in Bangladesh. BMC Public Health 2016;16:812.

22. Girdhar S, Sharma S, Chaudhary A, et al. An epidemiological study of overweight and obesity among women in an urban area of north India. Indian J Community Med 2016:41:154-7.

23. Bhanji S, Khuwaja AK, Siddiqui F, et al. Underestimation of weight and its associated factors among overweight and obese adults in Pakistan: a cross sectional study. BMC Public Health 2011;11:363.

24. Balarajan $\mathrm{Y}$, Villamor $\mathrm{E}$. Nationally representative surveys show recent increases in the prevalence of overweight and obesity among women of reproductive age in Bangladesh, Nepal, and India. J Nutr 2009;139:2139-44.

25. Eisenmann JC, Bartee RT, Wang MQ. Physical activity, TV viewing, and weight in U.S. youth: 1999 Youth Risk Behavior Survey. Obes Res 2002;10:379-85.

26. Dennison BA, Erb TA, Jenkins PL. Television viewing and television in bedroom associated with overweight risk among low-income preschool children. Pediatrics 2002;109:1028-35.

27. Ghavamzadeh S, Khalkhali HR, Alizadeh M. TV viewing, independent of physical activity and obesogenic foods, increases overweight and obesity in adolescents. $J$ Health Popul Nutr 2013;31:334-42.

28. Inoue $\mathrm{S}$, Sugiyama $\mathrm{T}$, Takamiya $\mathrm{T}$, et al. Television viewing time is associated with overweight/obesity among older adults, independent of meeting physical activity and health guidelines. $J$ Epidemiol 2012;22:50-6.

29. Veitcha J, Abbotta G, Kaczynski AT, et al. Park availability and physical activity, TV time, and overweight and obesity among women: findings from Australia and the United States. Health Place 2016;38:96-102.

30. Caroli M, Argentieri L, Cardone M, et al. Role of television in childhood obesity prevention. Int J Obes Relat Metab Disord 2004;28(Suppl 3):S104-8.

31. Ekelund $\mathrm{U}$, Brage $\mathrm{S}$, Froberg $\mathrm{K}$, et al. TV viewing and physical activity are independently associated with metabolic risk in children: the European Youth Heart Study. PLoS Med 2006; 3:e488. 